\title{
Using dual-frequency sonar to detect juvenile goliath grouper Epinephelus itajara in mangrove habitat
}

\author{
Sarah Frias-Torres ${ }^{1,2, *}$, Jiangang Luo ${ }^{1}$ \\ ${ }^{1}$ University of Miami, Rosenstiel School of Marine and Atmospheric Science, 4600 Rickenbacker Causeway Miami, \\ Florida 33149, USA \\ ${ }^{2}$ Present address: Ocean Research and Conservation Association (ORCA), 1420 Seaway Drive, Fort Pierce, \\ Florida 34949, USA
}

\begin{abstract}
We tested alternative methods to diver visual censuses of juvenile goliath grouper Epinephelus itajara in turbid mangrove habitat. We used a dual-frequency identification sonar (DIDSON) acoustic camera. DIDSON generates high resolution images of fish with a high-frequency multibeam sonar. The system can record the shape, size and movement of fish under low visibility conditions. A paired DIDSON-digital underwater video camera system was used to survey the mangrove shorelines of Niles Channel, in the Lower Florida Keys, USA. In high visibility conditions, the specific E. itajara DIDSON acoustic signal was obtained and used to evaluate DIDSON's performance for E. itajara surveys in turbid conditions. Under both clear and turbid conditions DIDSON enabled the quantification and measurement of juvenile E. itajara in mangrove undercuts and submerged dead trees that were not visible or detected using video or by a diver. DIDSON could not detect immobile juveniles, as it was unable to discern them from the substrate or the underwater structures where they rested. We demonstrate that mangrove microhabitat underwater structures do not interfere with acoustic fish signals. This study represents the first known successful application of a DIDSON acoustic camera in mangrove shorelines to achieve juvenile $E$. itajara detection and sizing.
\end{abstract}

KEY WORDS: Epinephelus itajara $\cdot$ Rhizophora mangle $\cdot$ Jewfish $\cdot$ Behavior $\cdot$ DIDSON $\cdot$ Video · Florida

\section{INTRODUCTION}

The goliath grouper (jewfish) Epinephelus itajara is a mangrove-dependent reef fish. Juveniles $(<110 \mathrm{~cm}$ total length, TL) are found along fringing red mangrove Rhizophora mangle shorelines, while adults (>110 cm TL) inhabit coral reefs, reef/rock ledges and artificial structures. Strong habitat dependence on mangroves combined with the life history traits of slow growth, long life span (3 or 4 decades), late sexual maturity (5 to 8 yr) and high site fidelity (Sadovy \& Eklund 1999) make the species extremely vulnerable to overfishing and habitat degradation. The species is critically endangered throughout its distribution area of tropical/subtropical eastern and western Atlantic
Ocean, except in Florida, where the species has benefited from a fishing ban in US waters since 1992 (TakChuen \& Ferrera 2007).

Juvenile mangrove dependence is one of the primary bottlenecks to Epinephelus itajara recovery (Koenig et al. 2007). Turbidity in mangrove habitats has limited $E$. itajara field surveys to the use of traps, hook and line, and telemetry in southwest Florida (Eklund 2005, FriasTorres et al. 2007, Koenig et al. 2007), Belize (Graham et al. 2009, this Theme Section) and Brazil (Hostim-Silva et al. 2005). However, water visibility of $250 \mathrm{~cm}$ or more has allowed the use of visual underwater techniques to determine habitat association of juvenile E. itajara in the mangroves of the Florida Keys, USA (Frias-Torres 2006). The aim of the present study was to test alternative 
sampling methods to diver visual censuses for juvenile E. itajara surveys in turbid mangrove habitats.

The dual-frequency identification sonar (DIDSON) acoustic camera, initially developed for the US Department of Defense (Belcher et al. 2001), is a high frequency multibeam sonar (96 at $1.8 \mathrm{MHz}$ and 48 at 1.0 MHz) with a unique acoustic lens system designed to focus the beam to generate high resolution images (Mueller et al. 2006). The system can record the shape, size and movement of targets (e.g. fish) and function under low visibility conditions (turbid water and/or night surveys). Researchers have used DIDSON systems to quantify migrating salmonid upstream passage (Belcher et al. 2001, Maxwell \& Gove 2007) and detect fish under ice (Mueller et al. 2006). From previous Epinephelus itajara visual underwater surveys in the mangroves of the Florida Keys (Frias-Torres 2006) we knew juveniles had a unique morphological profile and behavioral display. We suspected such profile and range of behaviors could provide a unique acoustic signal in DIDSON. Comparing simultaneous video and DIDSON images of E. itajara in good visibility conditions would make it possible to match the acoustic signal with visual identification of the species. Once the acoustic signal was confirmed, DIDSON could be used in situations of low visibility. Therefore, the objectives of our study were to determine whether E. itajara displayed a unique acoustic signal in DIDSON and to evaluate the feasibility of using DIDSON to detect E. itajara in turbid mangrove habitats.

\section{MATERIALS AND METHODS}

This study was conducted 14 to 15 June 2006 in a section of Niles Channel of the Lower Florida Keys between latitudes $24^{\circ} 45^{\prime} \mathrm{N}$ and $24^{\circ} 37.5^{\prime} \mathrm{N}$, and longitudes $81^{\circ} 27.5^{\prime} \mathrm{W}$ and $81^{\circ} 22.5^{\prime} \mathrm{W}$, within the Florida Keys National Marine Sanctuary (Fig. 1). The region selected contains overwash red mangrove Rhizophora mangle islands, where tidal waters overwash the islands in almost every tidal cycle and tidal currents often erode the peat deposits forming underwater ledges or undercuts (Gilmore \& Snedaker 1993). See Frias-Torres (2006) for further study area details. Epinephelus itajara microhabitats surveyed included undercuts and submerged dead trees (Fig. 1). Site selection was non-random and built on the results of Frias-Torres (2006) and Frias-Torres et al. (2007) to ensure E. itajara presence. We installed a digital video camera above a DIDSON unit and attached the setup to a PVC pipe. The video camera was a Sony ${ }^{\circledR}$ DCRVX2000 inside an Amphibico ${ }^{\circledR}$ housing. The camera lens had a 6 to $72 \mathrm{~mm}$ focal length and recorded as a 24 $\mathrm{mm}$ wide-angle lens. The DIDSON system used multiple narrow hydroacoustic beams ( 96 at $1.8 \mathrm{MHz}$ and 48 at $1.0 \mathrm{MHz}$ ) to produce high resolution, nearfield image video streams. Thus the highest resolution available to analyze DIDSON images is achieved by using the video streams in the original DIDSON software. In order to facilitate data analysis and interpretation, it is important to understand the difference
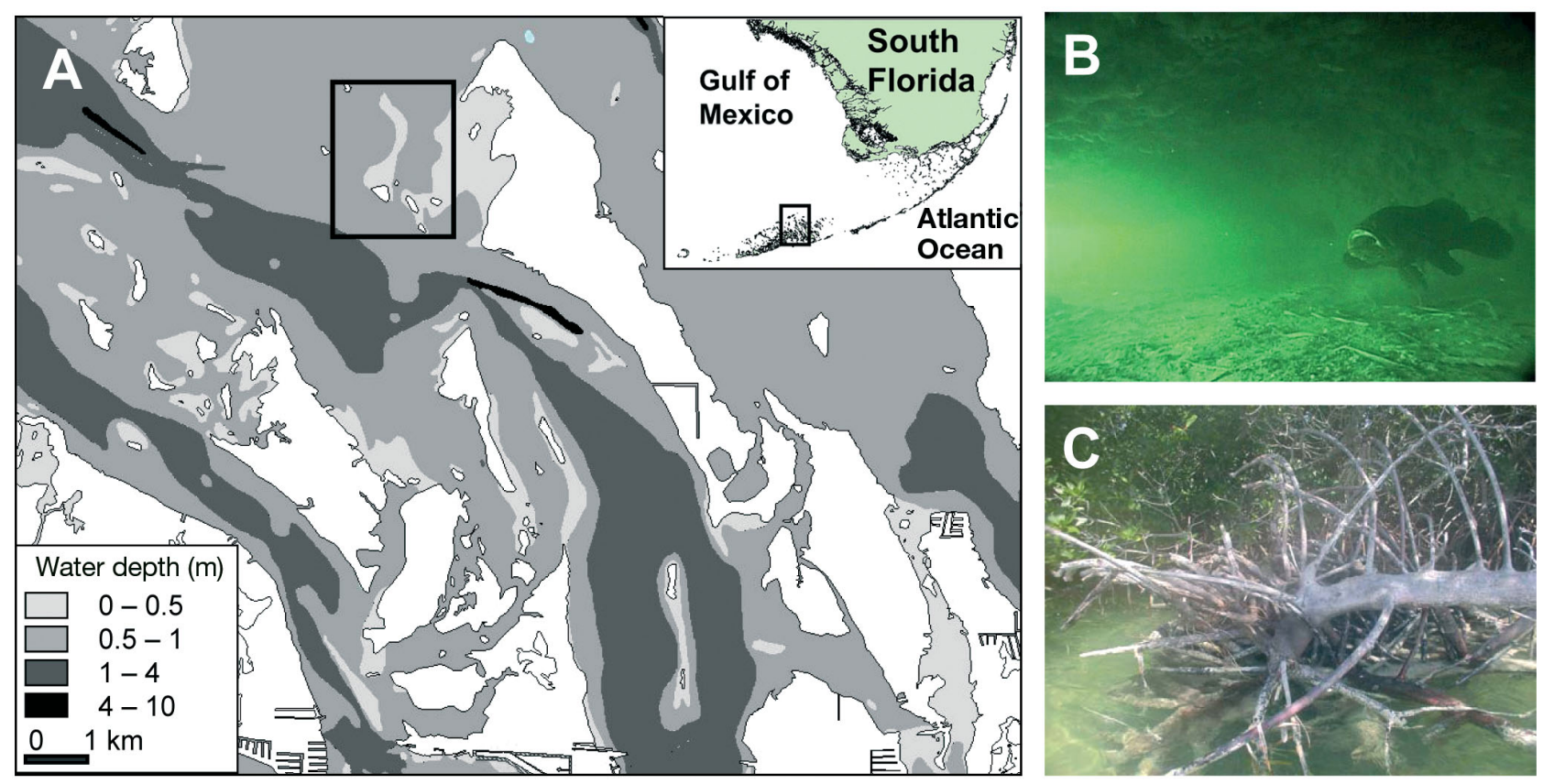

Fig. 1. Study area. (A) South Florida (inset) and Florida Keys with area studied (rectangle) within Niles Channel. Mangrove microhabitats surveyed included (B) undercuts, E. itajara shown and (C) submerged dead trees 
between a standard video camera lens and an acoustic camera lens (DIDSON). The point of view (POV) of a video camera lens translates a 3-dimensional image (the real world) into a 2-dimensional space along $x$ and $y$ axes. We are mostly familiar with this type of translation when looking at a photograph or a movie. However, the POV of an acoustic lens performs the 2dimensional translation along $x$ and $z$ axes. As a result, objects appear with a slight aerial perspective (as if seen from above). Fish that look straight into the DIDSON lens may appear in a characteristic 'head-down' position.

On site, a diver visually inspected the undercut or dead tree to confirm the presence of juvenile Epinephelus itajara. The diver then carried the DIDSON-video setup and the attached DIDSON cable, and deployed the system within $2 \mathrm{~m}$ of the undercut entrance or the dead tree by vertically inserting the PVC pipe in the soft bottom. At that time, underwater visibility was determined as either clear $(>250 \mathrm{~cm})$ or turbid $(\leq 250$ $\mathrm{cm}$ ). The video camera was monitored by the diver and the DIDSON was monitored by an operator in an attendant $8 \mathrm{~m}$ long vessel. The DIDSON-video unit was tilted at a $15^{\circ}$ angle down from the water surface to improve DIDSON target detection.

The digital video was captured from the master miniDV tape on a PC with a Sony Video Walkman through an IEEE 1394 (Firewire) interface using Microsoft Windows Movie Maker v.5.1 software. Timecode was preserved and video clips matched to a corresponding DIDSON file and saved as Microsoft Windows Media Player v.10 files. Both video and DIDSON files were saved in 5 min time segments to facilitate the use of standard methods of video analysis (Lehner 1998). TL of each fish was measured using the DIDSON software measuring tool. When measuring fish size distribution, care was taken not to measure repeats on the same file. This was possible by following the movements of individuals in the DIDSON movie output. The null hypothesis was that both video and DIDSON detected the same number of juvenile Epinephelus itajara per 5 min of observation (variable) in either clear or turbid water conditions. Statistical analyses were performed using Statistica 6.0 computer software. Original count data were tested for the assumptions of normality and equal variance required in parametric tests. Data met parametric test requirements. To test for differences in the number of $E$. itajara observed per 5 min DIDSON versus video, in both turbid and clear conditions, we used a $t$-test for independent samples. The Pearson correlation coefficient (Sokal \& Rohlf 1995) was used to examine the relationship between the number of E. itajara detected by DIDSON and by video in both turbid and clear water conditions.

\section{RESULTS}

A total of 18 juvenile Epinephelus itajara were found, with a mean TL of $56.4 \mathrm{~cm}$ (range 33 to $90 \mathrm{~cm}$ TL). The paired DIDSON-video system recorded $1 \mathrm{~h}$ $43.5 \mathrm{~min}$ of underwater footage, of which $1 \mathrm{~h}$ and 4.5 min contained 1 or more E. itajara in either DIDSON, video or both. Images not containing E. itajara were discarded from this study. The unused DIDSON/ video corresponds to situations in which the fish seen upon initial diver inspection had fled the site once the system was installed. Paired DIDSON-video images confirmed a distinct species-specific DIDSON acoustic signal of juvenile E. itajara, consisting of a large head and rounded pectoral fins, as opposed to the more slender signal of co-occurring gray snapper Lutjanus griseus (Fig. 2; see Video 1, available as Supplementary Material at www.int-res.com/articles/suppl/ esr00138_app/). Due to the different system of image capture and POV between the video camera lens and the DIDSON acoustic lens (see 'Materials and methods'), E. itajara showed an apparent 'head-down' position in DIDSON images (Figs. 2 \& 3; Supplementary Material: Videos 1 to 3).

Eleven DIDSON files were 5 min long, while 3 files were 2.5 or $3.5 \mathrm{~min}$ long. These files were matched with their corresponding video files and classified as either 'clear' (4 files) or 'turbid' (10 files) conditions. In turbid conditions, the number of juvenile Epinephelus itajara detected was significantly higher using DIDSON than using video $\left(\mathrm{n}_{\text {DIDSON }}=\mathrm{n}_{\text {video }}=10, t=3.537\right.$, $\mathrm{df}=18, \mathrm{p}=0.002)$ but was similar in high visibility or clear conditions $\left(\mathrm{n}_{\text {DIDSON }}=\mathrm{n}_{\text {video }}=4, t=0.361, \mathrm{df}=6\right.$, $\mathrm{p}=0.730$ ) (Fig. 4). Correlation between DIDSON and video detections was not statistically different in turbid $\left(\mathrm{n}_{\text {turbid }}=10, \mathrm{r}=0.0402, F_{1,8}=0.013, \mathrm{p}=0.912\right)$ or clear (n $\mathrm{n}_{\text {clear }}=4, \mathrm{r}=0.522, F_{1,2}=0.75, \mathrm{p}=0.478$ ) conditions (Fig. 5), with the correlation coefficient in clear conditions considered modest, although not significant (Sokal \& Rohlf 1995). Under turbid conditions, video observations resulted in underestimates of abundance relative to DIDSON. Under clear conditions, DIDSON could not detect individuals located less than $1 \mathrm{~m}$ from the setup, but video camera could. Under both clear and turbid conditions, however, DIDSON could detect fish that were hiding from the observer deep in undercuts or in submerged tree roots and branches (Figs. 2 \& 3; Videos 1 to 3).

\section{DISCUSSION}

Paired DIDSON-video images allowed identification of a characteristic DIDSON acoustic signal for Epinephelus itajara, while the size distribution was within 

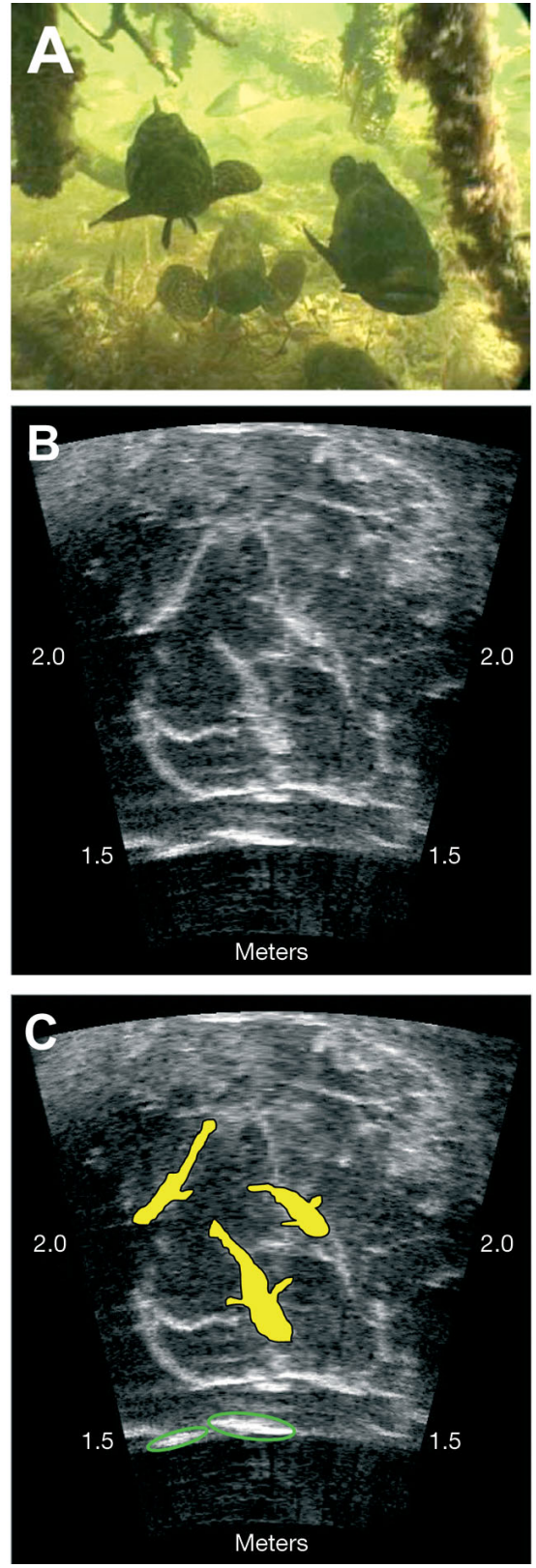

Fig. 2. Epinephelus itajara. Paired DIDSON-video images of 3 E. itajara in clear conditions at a submerged dead tree in (A) video and (B) DIDSON reveal distinct DIDSON acoustic signal for the species; (C) illustrates the DIDSON image from (B) with the shape of the $3 \mathrm{E}$. itajara highlighted in yellow exhibiting characteristic big head and rounded pectoral fins. The acoustic E. itajara signal can be compared to the more slender signal of gray snappers Lutjanus griseus (green ovals). The apparent 'head-down' position of E. itajara in the DIDSON image, contrasting with the face-to-face view of the video image ( $x$ and $y$ axes point of view) is due to the visual effect of the aerial perspective, or $x$ and $z$ axes point of view, of the acoustic lens. Tree branches are shown at the top and left side of the DIDSON images. Frames are within the same time segment but different seconds (See also Video 1, available as Supplementary Material at www.int-res.com/ articles/suppl/esr00138_app/) the values obtained in previous studies in the same area (Frias-Torres 2006). Species identification is not always possible when using DIDSON, in particular when fish species are morphologically similar (Belcher et al. 2001). Under both clear and turbid conditions, DIDSON enabled the quantification and measurement of juvenile $E$. itajara in mangrove undercuts and among the branches of submerged dead trees that were not visible or detected using video or by a diver. DIDSON could not detect immobile juveniles; it was unable to discern them from the substrate or the underwater structures where they were resting. Video fish detections not found in DIDSON were a result of DIDSON's narrow field of view $\left(29^{\circ}\right)$ at close range, while video cameras with a wide-angle lens can detect fish presence in the near field $(<1 \mathrm{~m})$ (Mueller et al. 2006).

DIDSON images allowed the recording of undisturbed Epinephelus itajara behavior and microhabitat association. After the initial disturbance during experimental setup, the diver did not interact further with the fish; DIDSON video streams provided a record on juvenile E. itajara site attachment, inter and intraspecies behavioral interactions (see Supplementary Material: Videos 1 to 3). DIDSON also worked as a third observer, recording juvenile E. itajara behavior in the presence of divers with professional underwater cameras and lighting (Video 3).

We demonstrated that mangrove microhabitat underwater structures did not interfere with acoustic fish signals. Dead tree branches and undercuts were distinctly observed in DIDSON video streams, allowing a continuous record of juvenile Epinephelus itajara habitat association and habitat-specific behavior. Previous DIDSON-video comparison studies in sites with potential habitat signal obstruction have included ocean inlets, lakes, rivers and streams with ice cover; tilting the DIDSON lens at a $15^{\circ}$ angle down from the horizontal (as in our study) maximized fish detection (Crawford \& Jorgenson 1990, Mueller et al. 2006). However, the majority of previous fish-specific DIDSON studies, used to quantify migrating salmonid upstream passage (Foote 1987, Belcher et al. 2001, Maxwell \& Gove 2007), did not test DIDSON in conditions with the high underwater structural complexity found in mangroves.

Visual underwater surveys of juvenile Epinephelus itajara have revealed critical distribution patterns and mangrove microhabitat associations at a fine detail that is unattainable by using traps, hook and line or telemetry alone (Frias-Torres 2006). An experienced diver with a digital video camera can closely approach juvenile E. itajara and follow them into deep undercuts, or record the immobile individuals resting on the bottom or among mangrove roots. But this type of 


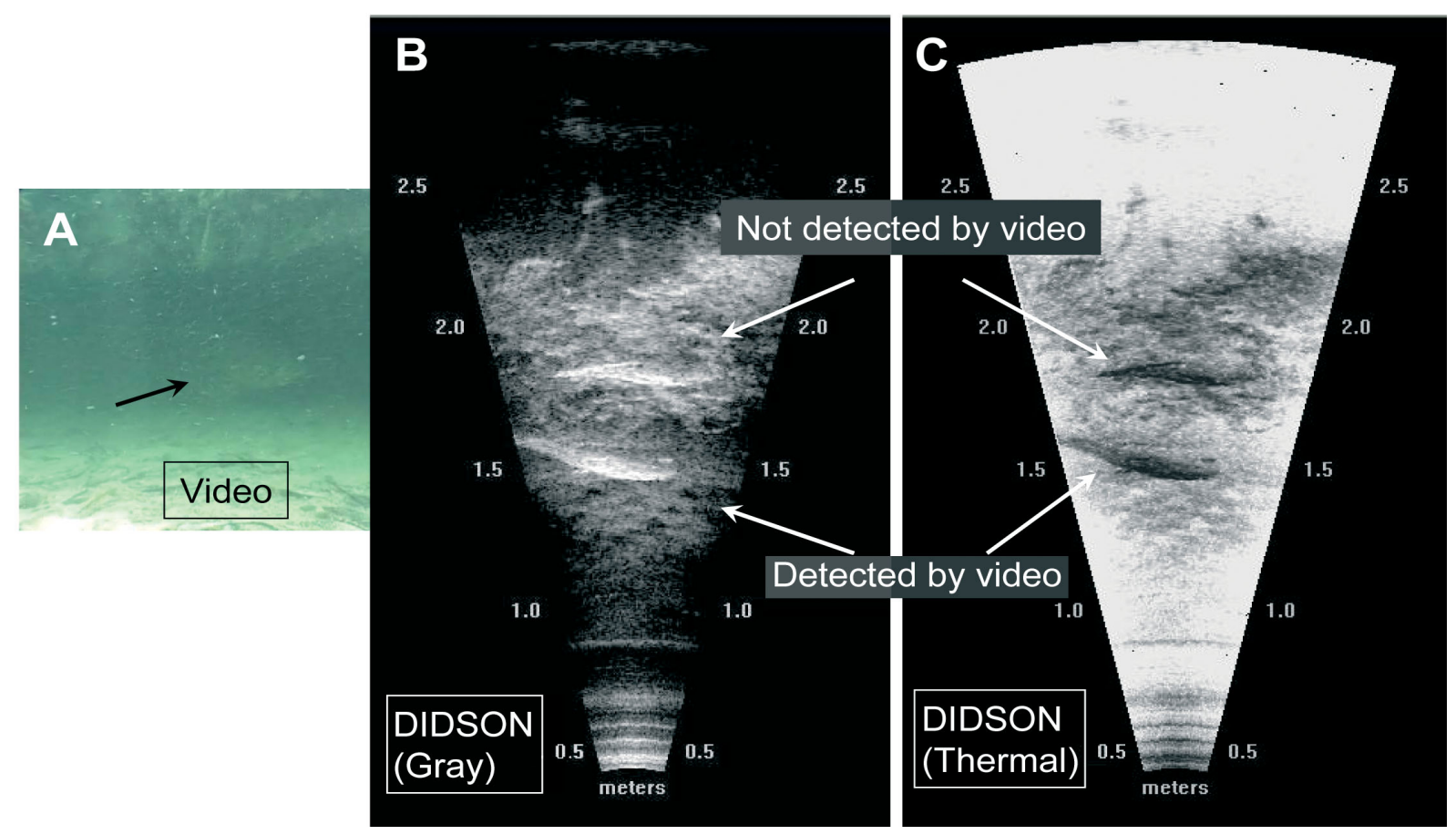

Fig. 3. Epinephelus itajara. Paired DIDSON-video images in turbid conditions at the entrance of an undercut. Video image (A) and 2 different DIDSON displays are shown: (B) grey and (C) thermal. The rugged background in the DIDSON images is the signal from the undercut ceiling. Time frames are identical (See also Videos 2 \& 3, available as Supplementary Material at www.int-res.com/articles/suppl/esr00138_app/)

visual census only works with visibilities of $250 \mathrm{~cm}$ or more. A combination of DIDSON and video cameras may be useful when surveying juvenile E. itajara in mangrove habitats with low to moderate turbidity. The more limited range of the video camera is useful to detect fish that are too close for the acoustic camera to detect. At zero visibility, DIDSON is the only tool available to provide visual input. However, due to the high

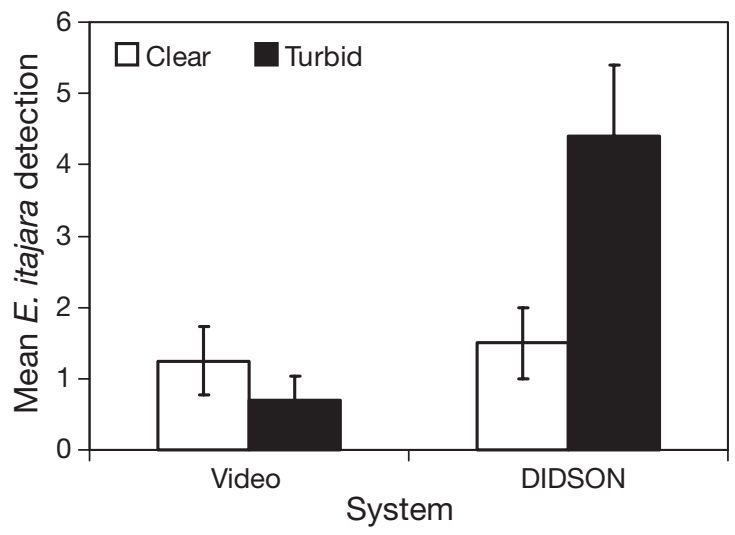

Fig. 4. Epinephelus itajara. Number of fish detections per 5 min of observation time, comparing detections in clear versus turbid conditions in both video and DIDSON; $t$-test was significant $(p<0.05)$ for DIDSON. Values are means \pm SE equipment costs, DIDSON-based surveys may be costeffective in areas where more traditional techniques (divers, traps, hook and line) have provided initial input on E. itajara occurrence and distribution, and more detailed information is required. Our study represents the first known successful application of a DIDSON acoustic camera in mangrove shorelines that achieved juvenile E. itajara detection and sizing.

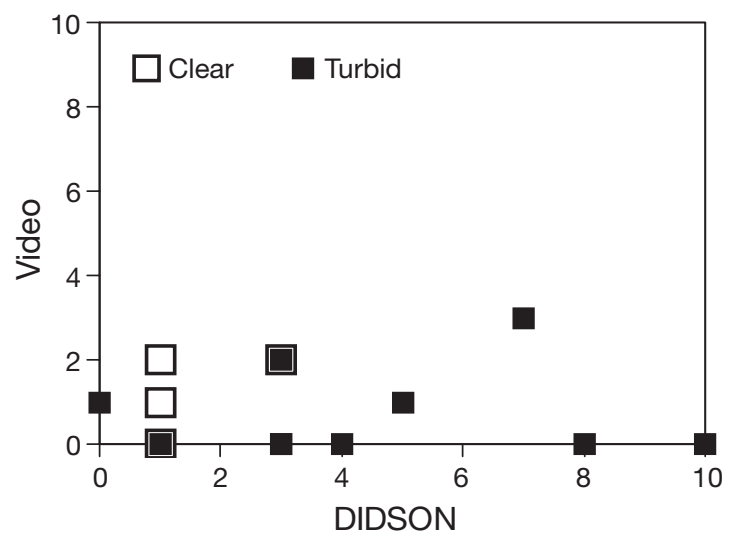

Fig. 5. Epinephelus itajara. Correlation between number of DIDSON and video E. itajara detections per 5 min of observation time in clear and turbid conditions. Correlation coefficients were not significant $(p>0.05)$ 
Acknowledgements. We thank M. Laudicina, P. Johnson, R. Boonstra and Talbot Films for their assistance during fieldwork in the Florida Keys. We also thank J. E. Serafy and 4 anonymous reviewers for comments that improved earlier versions of this manuscript. Funding was provided by the NOAA Fisheries' Coral Reef Conservation Program. Views expressed herein are those of the authors and do not necessarily reflect the views of any supporting agency.

\section{LITERATURE CITED}

Belcher EO, Matsuyama B, Trimble GM (2001) Object identification with acoustic lenses. In: An ocean odysseyOceans 2001 MTS/IEEE Conf Proc, Vol 1. Marine Technology Society, Washington, DC, p 6-11

Crawford RE, Jorgenson J (1990) Density distribution of fish in the presence of whales at the Admiralty Inlet landfast ice edge. Arctic 43:215-222

Eklund AM (2005) Habitat affinities of juvenile goliath grouper to assess estuarine conditions. In: Bortone SA (ed) Estuarine indicators. CRC Press, Boca Raton, FL, p 393-407

Foote KG (1987) Fish target strengths for use in echo integration surveys. J Acoust Soc Am 82:981-987

Frias-Torres S (2006) Habitat use of juvenile goliath grouper Epinephelus itajara in the Florida Keys, USA. Endang Species Res 2:1-6

Frias-Torres S, Barroso P, Eklund AM, Schull J, Serafy J (2007) Activity patterns of three juvenile goliath grouper Epinephelus itajara in a mangrove nursery. Bull Mar Sci 80:587-594

Gilmore RG, Snedaker SC (1993) Mangrove forests. In: Echternacht AC (ed) Biodiversity of the Southeastern

Editorial responsibility: Brendan Godley,

Penryn, UK
United States: lowland terrestrial communities. John Wiley \& Sons, New York, p 165-198

Graham RT, Rhodes KL, Castellanos D (2009) Characterization of the goliath grouper Epinephelus itajara (Lichtenstein, 1822) fishery of southern Belize for conservation planning. Endang Species Res 7:195-204

- Hostim-Silva M, Bertoncini AA, Gerhardinger L, Machado LF (2005) The 'Lord of the Rock's' conservation program in Brazil: the need for a new perception of marine fishes. Coral Reefs 24:74

Koenig CC, Coleman FC, Eklund AM, Schull J, Ueland J (2007) Mangroves as essential nursery habitat for goliath grouper (Epinephelus itajara). Bull Mar Sci 80:567-586

Lehner P (1998) Handbook of ethological methods. Cambridge University Press, New York

$>$ Maxwell SL, Gove NE (2007) Assessing a dual-frequency identification sonar's fish-counting accuracy, precision and turbid river range capability. J Acoust Soc Am 122:3364-3377

Mueller RP, Brown RS, Hop H, Moulton L (2006) Video and acoustic camera techniques for studying fish under ice: a review and comparison. Rev Fish Biol Fish 16:213-226

Sadovy Y, Eklund AM (1999) Synopsis of biological data on the Nassau grouper, Epinephelus striatus (Bloch, 1792), and the jewfish, E. itajara (Lichtenstein, 1822). NOAA Tech Rep NMFS 146, Seattle, WA

Sokal RR, Rohlf FJ (1995) Biometry: the principles and practices of statistics in biological research, 3rd edn. W.H. Freeman \& Co., New York

Tak-Chuen TC, Ferrera BP (2007) Epinephelus itajara. In: IUCN 2007. 2007 International Union for Conservation of Nature Red List of Threatened Species. www. iucnredlist.org

Submitted: February 19, 2008; Accepted: September 4, 2008 Proofs received from author(s): October 23, 2008 